\title{
Seniors' experiences of visual art environmental enrichment
}

\author{
Lars Olov Bygren ${ }^{1,2}$, Birgitta Näsman², Britt-Maj Wikström ${ }^{3 *}$, Benson B. Konlaan ${ }^{4}$, \\ Ann-Brith Karlsson ${ }^{2}$, Eva Elgh ${ }^{2}$, Andrej M. Grjibovski ${ }^{5,6}$, Sven Sandström ${ }^{7}$ \\ ${ }^{1}$ Department of Biosciences and Nutrition, Karolinska Institute, Huddinge, Sweden \\ ${ }^{2}$ Department of Community Medicine and Rehabilitation, University of Umeå, Umeå, Sweden \\ ${ }^{3}$ Oslo and Akershus University College, Faculty of Health Sciences, Oslo, Norway \\ ${ }^{4}$ Swedish Red Cross University College of Nursing, Stockholm, Sweden \\ ${ }^{5}$ Norwegian Institute of Public Health, Oslo, Norway \\ ${ }^{6}$ International School of Public Health, Northern State Medical University, Arkhangelsk, Russia \\ ${ }^{7}$ Department of Art History, University of Lund, Lund, Sweden \\ Email: "britt-maj@home.se
}

Received 17 January 2013; revised 15 March 2013; accepted 10 April 2013

Copyright (c) 2013 Lars Olov Bygren et al. This is an open access article distributed under the Creative Commons Attribution License, which permits unrestricted use, distribution, and reproduction in any medium, provided the original work is properly cited.

\begin{abstract}
The present study aimed at determining whether short-term exposure to art in shared common areas in congregate housing units could affect health and health determinants among the residents. Ten residents (mean age 80.4 years) at one block were exposed to visual art environmental enrichment in common areas over a period of three months. Thirteen persons (mean age 86.6 years) living in another block played in-house boule. Cornell's test, Mini-Mental tests (MMT), and face recognition test were performed to assess depression, cognition, and episodic memory, respectively before and after the intervention. The results show that visual art environmental enrichment in common areas and lack of stimulating and guiding dialogues show a change in depression scores in the intervention group $(p=0.018)$ and the control group $(p=0.009)$. MMT scores improved only in the control group $(p=0.003)$. No changes in episodic memory in any of the groups were observed. It could be concluded that in order to obtain a positive result of short term visual art environmental enrichment, guiding art dialogues conducted by nurses, as described in previous research, should be added to visual art environmental enrichment in healthcare settings.
\end{abstract}

Keywords: Health Professionals; Elderly; Depression; Visual Art; Environmental Enrichment; Memory

\footnotetext{
*Corresponding author.
}

\section{INTRODUCTION}

Coherence between health and participation in cultural life has been demonstrated in population-based studies [1] and this enjoyment is instrumental for health improvement among the elderly [2]. Art in the form of paintings is one important source of stimulation from such participation [3].

The environment has an impact on our lives and there is a growing acceptance of the vital role patient centered design plays in shaping the environment. The physical environment is always present and can affect the body both physiologically and psychologically by what we take in and interpret through our senses. A helpful environment shall promote acts of caring. It is the nurse's responsibility to develop a nourishing healthcare environment and consider the aesthetic aspects of the healthcare environment [4]. Art should be incorporated into every area of the healthcare environment. Previous research points at successful results [5-10]. It is within the power of each person to share and interpret experience by means of the arts, by viewing the work of others, and by using feelings and imagination and increasing the understanding of what the world has to offer. Today research shows that visual art could be used in order to stimulate the dialogue between a patient and a nurse, infuse new topics to talk about. Good art in health care settings engages the users in dialogues. Supportive design promotes stress reduction, a documented problem for patients, families and visitors as well as healthcare members of the health care staff.

Long term exposure to reproductions of art, combined with a conversation more or less initiated by the paint- 
ings, has shown to have health effects on elderly women [3]. In addition, it is an appreciated tool for conversation amongst caregivers [5]. It is however unknown whether short-term exposures can have similar effects.

\subsection{Purpose of the Study}

The present study aimed at determine whether short-term exposure to visual art environmental enrichment in shared common areas in congregate housing for old people could affect health and health determinants among the residents.

\subsection{Congregate Housing for Old People in Sweden}

The congregate housing units were introduced during the 1960s and replaced old-age homes, where the residents had one small room only. The old terminology of "nursing home" and "sheltered living" was replaced by "congregate housing for old people”. Remodelling of existing units and construction of new congregate housing units for old people increased. Small home-like apartments for disabled persons were created, with living areas of about 35 square meters, consisting of spacious living room with a kitchenette, a bedroom and a hallway, and shared common areas (corridors, dining room, living room and kitchen).

\section{METHODS}

\subsection{Sampling}

The residents in one congregate housing units for old people were invited to take part in the visual art environmental enrichment intervention. In another congergate housing the residents were offered sessions of inhouse boule. The two units had been their home for many years prior to the study, they had similar socioeconomic background, and they all suffered from some degree of dementia. The residents were offered participation unless they were bed-ridden, had severe dementia or participated in a parallel study.

Works of art were placed in the common areas in the one congregate housing unit. In the other congregate housing unit the residents were offered to play in-house boule. All accepting participation could be allowed to participate because they constitute suitable groups; the in-house boule group $(n=13)$, and the visual art environmental enrichment group $(\mathrm{n}=10)$.

All residents with informed consent from the participant and relative, not being bedridden or severely demented in the two congregate housing units were exposed to either visual art environmental enrichment or in-house boule. The health professionals who took part in the study were nurses, aides and an occupational thera- pist. Approximately twenty health professionals were involved in the intervention. Those playing in-house boule was planned to be a contrast group given similar attention.

\subsection{Procedure}

The stimulation of the intervention group consisted of exposure to paintings in the common areas within the house. The paintings were borrowed during three months for their museal quality and possible cultural experience from the public art in the community. Members of the staff were trained in the use of art as a conversation tool [4]. They were asked to spend fifteen minutes per week conversing in front of a painting with one or two residents. The visual art was supposed to inspire the residents to find topics to discuss in order to lift forward the residents personal experiences. Visual art objects in the form of oil paintings ceramic images and aquarelles were placed in the ward to stimulate and create opportunities for dialogue through both visual and tactile means. Touch and tactile dimension was an important part of communication. The staff members were informed about the approach to invite patients to participate in the dialogue.

The control group, living in another block played inhouse boule, lasting for about 45 minutes per session. The in-house boule is an adaptation of a regular boule in which a ball is used, a sport where the goal is to roll balls closer to a smaller white ball than one's opponent is able to do. The residents in the congregate housing common area played an adapted form of boule. They played with a soft small ball while sitting on chairs or wheel-chairs in a wide ring. Volunteers from the local volunteer sector of healthcare workers' union were asked to arrange one session once a week.

\subsection{Assessments}

A specialist in geriatric medicine, together with the head nurses at the two congregate housing did assessments of the level of depression among the participants in the two groups; the art environmental enrichment group and the boule group, before and after the interventions. The Cornell's depression scale of dementia was used in the assessment that covered five dimensions; mood, behaviour, and physical signs [11,12]. The scale includes 19 items and the maximum score is 25 . A score of 8 or more suggests depression. The Mini-Mental Test [13] was used for assessing cognition. The episodic memory was evaluated by a face recognition test comprised of 15 faces of old and young males and females, presented one at a time for 5 seconds each. In the recognition test (after five minutes), these faces were again presented randomly intermixed with equal number of distracters. For each face, participants were asked to answer "yes" or "no" as 
to whether they recognized the face from the previous presentation. The score was equal to the number of hits (correct yes-responses) minus the number of false recognitions (incorrect yes-responses).

\subsection{Data Analyses}

Test scores before and after interventions were compared using paired t-tests and Wilcox signed rank tests for normally and non-normally distributed data respectively. Independent-samples t-tests and Mann-Whitney tests were used to compare unpaired measurements. Nominal variables were compared with Fisher's exact tests. All calculations were performed in SPSS, version 11.0 (SPSS Inc., Chicago, IL).

\subsection{Ethical Consideration}

The project was approved by the Regional Committee for Medical Research Ethics at the participating university. Data collection followed the declaration of Helsinki. Qualities that are judged include ethical perspective, research design, and the need in society for such a project. Informed consent was given by participants and relatives.

\section{RESULTS}

Among those qualified for the study, ten persons out of 30 elderly living in one of the two congregate housing units were recruited and they served as the visual art environmental enrichment group (intervention group). Thirteen persons out of the 39 living in the other congregate housing unit participated in boule sessions as contrast group. The control group (3 men and 10 women) was not significantly different from the intervention group (3 men and 7 women) at baseline with regard to gender, social background, age ( 80.4 vs. 86.6 years on average, $p$ $=0.187$ ) and episodic memory tests scores, but was less depressed and had higher cognition as presented in Table 1. In the intervention group six of the ten participants had no conversation in front of a painting, and four of the participants had one conversation in front of a painting. These conversations were not structured. Participants in the boule-playing group attended from 3 to 7 sessions.

The two groups were not case-controls in a strict meaning. They were contrast groups with equal attention but different kinds of interventions. They did not differ significantly in age but the point estimate differed 6 years. At baseline the Mini-Mental test differed by three points and there was a tendency to difference in the Cornell depression score and in depression percent. In summary those exposed to art were at baseline younger and less depressed than those exposed to in-house boule (Table 1).

The depression levels increased in the intervention group ( $\mathrm{p}=0.018$ ), and decreased in the control group ( $\mathrm{p}$ $=0.009$ ) resulting in significant differences between the changes observed as a result of the experiment $(\mathrm{p}<0.001)$ (Table 2). One of the ten participants was depressed before the experiment and another two developed depression during the intervention period. Among the thirteen participants in the control group six were depressed at the start and three of them were not depressed at the end of the intervention. None of the non-depressive in the control group at the start developed depression during the experiment.

Table 1. Means and standard deviations for episodic memory test, depression, and cognition at baseline before experiment in the group exposed to art and the group exposed to in-house boule.

\begin{tabular}{cccc}
\hline & Exposed to art M/F N = 3/13 & Boule-players M/F N = 3/10 & p \\
\hline Age, years & 80.4 & 86.6 & 0.187 \\
Episodic memory test scores & $6.4(4.7)$ & $6.3(4.9)$ & 0.964 \\
Cornell scores & $3.0(3.4)$ & $8.5(7.3)$ & 0.071 \\
Mini-Mental test scores & $27.5(2.1)$ & $24.2(4.4)$ & 0.029 \\
Depression, n (\%) & $1(10.0)$ & $6(46.2)$ & 0.089 \\
\hline
\end{tabular}

Table 2. Means and standard deviations for episodic memory test, depression test, and cognition tests before and after exposure to works of art and boule-playing respectively.

\begin{tabular}{|c|c|c|c|c|c|c|}
\hline & \multicolumn{3}{|c|}{ Works of art exposure } & \multicolumn{3}{|c|}{ Boule-playing } \\
\hline & Before & After & $\mathrm{p}$ & Before & After & $\mathrm{p}$ \\
\hline Episodic memory scores & $6.4(4.7)$ & $7.1(4.5)$ & n.s. & $6.3(4.9)$ & $7.2(4,6)$ & n.s. \\
\hline Cornell's score of depression & $3.0(3.4)$ & $6.0(6.0)$ & 0.018 & $8.5(7.3)$ & $4.2(5.8)$ & 0.009 \\
\hline The depression score more than 7, n (\%) & $1(10.0)$ & $3(30.0)$ & n.s. & $6(46.2)$ & $3(23.1)$ & n.s. \\
\hline Mini-Mental test scores & $27.5(2.1)$ & $27.8(1.9)$ & n.s. & $24.2(4.4)$ & $26.9(3.5)$ & 0.003 \\
\hline
\end{tabular}

n.s. Not significant at the level of alpha error of 5\% Jag kan inte få upp standarddeviationerna som har hamnat raden under, ser du det? Första sifferraden 6.3 (4.9) ska det va'etc. 
The results of the test of face recognition slightly improved in both groups, though these changes were not significant in the intervention group or the control group.

The results of Mini-Mental test did not improve in the intervention group ( $p=0.671$ ), but did so in the control group ( $p=0.003$ ). The difference between the changes observed was significant $(p=0.008)$.

\section{Summary of Results}

Environmental enrichment with works of art in the intervention group, and boule sessions in the control group show positive outcome according to depression in the boule group compared to the art environmental enrichment group. Social contact with health professionals differed between the two groups, with regular weekly contacts in the boul control group. The visual art environmental enrichment group had no structured conversations in front of a painting.

\section{DISCUSSION}

An increased depression was found among the participants in the visual arts environmental enrichment group and a decreased depression was found in the control group, which was stimulated by in-house boule sessions. The results bring questions on whether the short-term art environmental enrichment as well as lack of structured conversations generated by a painting is ineffective in relation to the studied outcomes. The intervention with stimulating dialogues was not performed as planned. The art environmental enrichment was too passive, meaning lacking enough introduction of the art works.

Those who were exposed to art, who at baseline was less depressed, became more depressed, while those who were playing boule, who at baseline were more depressed, improved as to depression (Table 2). It could be that the baseline level depressions was the cause of the difference in effect but further discussion on a possible increase in depression among elderly exposed to art is warranted.

In previous studies showing positive effects of art environmental enrichment on health outcomes, special attention was paid to the intensity and length of the intervention and the role of the conversation leader to support and encourage the elderly persons to combine earlier memories and experiences with new impressions from the paintings [3,4].

This procedure was not followed in the present study. It might to a certain extent explain the results. Previous studies showed the importance of how to conduct a conversation with the elderly person when using paintings. Decisive for a successful conversation with the elderly person is: which paintings capture your interest; pretend you are the artist, what it brings into your mind, etc. In the present study, the procedure described above was not followed. In addition the number of sessions in front of the paintings was lower than planned indicating lower intensity of the intervention [14].

The physical activation factor in boule sessions might have been a stimulating factor on the depression level. This makes the in-house boule activity not neutral compared to the art environmental enrichment. The activity included more of social interaction and more of physical influence than environmental enrichment with paintings. Both might have their place in the stimulation of senior citizens.

According the psychoanalytic theory, to symbolise emotions is important in order to take care of ourselves and in the extreme a lack of this ability is seen as alexithymi. The perception of works of art furthermore could give an opportunity of vivid fantasy pleasure in a socially accepted form [15]. Another path for the effects of art is by increasing the arousal, i.e. the level of attention, alertness and excitement by its appearance, by its association to survival and by its surprise and novelty effects [16]. The tension reduction theory points at the tension produced by art and which absorbs and combines with diffuse residual tensions in the spectator and are attended by relief of the tensions [17]. The communication theory of art views art as a way to objectify human feelings in order to understand the world of inner experience. This is achieved through symbols used in the art, thus differentiating it from the discursive.

The activities in the art environmental enrichment group differed from those in the control group. While the former were supposed to have dialogues individually with a staff member, the latter persons played games together, which involved group interactions.

Activities in leisure time [2] and precisely intellectual-cultural ones [16] may postpone dementia. However the experiment was of low intensity and of short duration. Animal research within this area suggests that in order to see beneficial effects, the exposure must be longer than three months as in the present study, given that the exposed individuals were more or less demented $[17,18]$. It has been demonstrated that short-time environmental enrichment of transgenic Alzheimer diseased mice increases the deposition of amyloidal plaques [19]. Long-term environmental enrichment results in improved cognition, independent of the amyloidal deposition or clearance [17, 18]. This difference in effects of short-term and longterm stimulation must be considered when cultural interventions are designed.

Art conversations performed by health professionals have positive impact on older adults' physical health status such as blood pressure and psychological well being $[3,14]$. An important structure of dialogues in the present study was that they were semi-structured. The 
typical initiation of the dialogue was the request to the older person; "I am interested in showing you some of the visual artworks in our ward that you and I can discuss as a topic of conversation. Which of these visual art objects captures your interest? Pretend you are the artist and know all about the work. What does it bring to your mind?”

One of the research group members in the present project [20] has found that a group who discusses current topics in newspaper articles, television and radio compared to a group who discusses visual art shows different communication directions. In the visual art dialogue group the dialogues change over time and catch increasingly more of the elderly persons' experience and knowledge. The visual art dialogues were characterized by imagination and happiness, and there was an inexhaustible source of topics originating from paintings that was discussed in this group. The control group members become very interested in discussing their physical health. The dialogues in this group were characterized by downheartedness, and it was difficult to find topics to conversation during the final phase of the studied period. Whether difference in age would affect the results of the present study could not be ruled out.

\section{CONCLUSION}

We conclude that the discrepancies between the results of this study and previous studies diverge. It indicates that short-term art environmental enrichment and/or visual art dialogues accompanying art environmental enrichment may not have been sufficient to observe beneficial effects for depression and cognition.

\subsection{Further Research}

In order to increase the possibility to achieve a positive outcome of art environmental enrichment, important factors seem to be either the length of the intervention and/ or the introduction of art stimulating dialogues.

\subsection{Implications for Nursing Care}

It is to be hoped that this study will contribute to the development of conversations between nurses and patients generated by visual art environmental enrichment. We must take into consideration the importance of a visual art dialogue, because it is related to a patient's experiences and expectations, it can have for nurses and patients. It could be a tool for nurses in their contact with a patient. We must though be cautious about making casual statements and continue to develop this research sector.

\section{ACKNOWLEDGEMENTS}

The authors acknowledge the support of the project by The Research
Programme Arts in Hospital and Care as Culture within Stockholm County Council.

\section{REFERENCES}

[1] Bygren, L.O., Konlaan, B.B. and Johansson, S.E. (1996) Attendance at cultural events, reading books or periodicals, and making music or singing in a choir as determinants for survival: Swedish interview survey of living conditions. British Medical Journal, 313, 1577-1580. doi:10.1136/bmj.313.7072.1577

[2] Fratiglioni, L., Paillard-Borg, S. and Winblad, B. (2004) An active and socially integrated lifestyle in late life might protect against dementia. Lancet, 3, 343-353. doi:10.1016/S1474-4422(04)00767-7

[3] Wikström, B.M., Theorell, T. and Sandström, S. (1993) Medical health and emotional effects of art stimulation in old age. Psychotherapy and Psychosomatics, 60, 195-206. doi:10.1159/000288693

[4] Wikström, B.M. (2003) Health professional's experience of paintings as a conversation instrument: A communication strategy at a nursing home in Sweden. Applied Nursing Research, 16, 184-188. doi:10.1016/S0897-1897(03)00049-1

[5] Daykin, N., Byrne, E., O’Conner, S. and Soteriou, T. (2008) The impact of art, design and environment in mental healthcare: A systematic review of the literature. The Journal of the Royal Society for the Promotion of Health, 128, 85-94. doi:10.1177/1466424007087806

[6] Lawson, B. and Wells-Thorpe, J. (2003) The architectural healthcare environment and its effects on patient health outcomes. HMSO Norwich, Norfolk.

[7] Williams, R.J. (2008) The declaration of Helsinki and public health. Bulletin of the World Health Organization, 86, 650-651. doi:10.2471/BLT.08.050955

[8] Weir, H. (2010) You don't have to like them: Art, tate modern and learning. Journal of Applied Arts and Health, 1, 93-110. doi:10.1386/jaah.1.1.93/1

[9] Weitz, M. (1976) Art: Who needs it? The Journal of Aesthetic Education, 10, 19-28. doi:10.2307/3332006

[10] Wells-Thorpe, J. (2002) Better by design, understanding the healing environment. Helix, 11, 23-27.

[11] Alexandropoulos, G.-S., Abrams, R.C. and Shamoian, C.A. (1998) Cornell scale for depression in dementia. Biological Psychiatry, 23, 271-284. doi:10.1016/0006-3223(88)90038-8

[12] Lam, C.K., Lim, P.P., Low, B.L., Ng, L.L., Chiam, P.C. and Sahadevan, S. (2004) In dementia: A validation study of four brief scales in the elderly Chinese. International Journal of Geratratric Psychiatry, 19, 422-428. doi:10.1002/gps.1098

[13] Folstein, M.F., Folstein, S.E. and McHugh, P.R. (1975) Mini-mental state: A practical method for grading the cognitive state of patients for the clinician. Psychiatric Research, 12,189-198. doi:10.1016/0022-3956(75)90026-6

[14] Wikström, B.M., Westerlund, E. and Erkilää, J. (2012) 
The healthcare environment: The importance of aesthetic surroundings, health professionals' experiences from a surgical ward in Finland. Open Journal of Nursing OJN, 2, 188-195. doi:10.4236/ojn.2012.23029

[15] Kreitler, H. and Shulamit, I. (1972) Psychology of the arts. University Press, Durham.

[16] Winner, E. (1982) Invented worlds: The psychology of the arts. Harvard University Press, Cambridge.

[17] Arendash, G.W., Garcia, M.F., Costa, D.A., Gracchiolo, J.R., Wefes, I.M. and Potter, H. (2004) Environmental enrichment improves cognition in aged Alzheimer's transgenic mice despite beta-amyloid deposition. Neuroreport, 15, 1751-1754. doi:10.1097/01.wnr.0000137183.68847.4e
[18] Jin, K., Galvan, V., Xie, L., Mao, X.O., Gorostiza, O.F. and Bredesen, D.E. (2004) Enhanced neurogenesis in Alzheimer's disease transgenic mice, Proceedings of the National Academy of Sciences, 101, 13363-13367. doi:10.1073/pnas.0403678101

[19] Jankowsky, J.L., Xu, G., Fromholt, D., Gonzales, V. and Borchelt, D.R. (2003) Environmental enrichment exacerbates amyloid plaque formation in a transgenic mouse model of Alzheimer disease. Journal of Neuropathology and Experimental Neurology, 62, 1220-1227, 2003.

[20] Wikström, B.M. (2000) Visual art dialogues with elderly persons: Effects on perceived life situation. Journal of Nursing Management, 8, 31-37. doi:10.1046/j.1365-2834.2000.00154.x 